\section{National cholesterol guidelines enhance treatment}

In the last 20 years the National Heart, Lung, and Blood Institute, through the National Institutes of Health, has greatly increased its activity in the field of preventive medicine concerning cardiovascular diseases. They started a no smoking program approximately 20 years ago, a program for lowering high blood pressure about 10 or 12 years ago, and more recently, guidelines for lowering cholesterol which has a causal effect on atherosclerosis, specifically coronary heart disease.

Following the publication of the results of the primary coronary prevention trials, plus many other large, well-controlled studies on cholesterol and its effect upon atherosclerosis and coronary artery disease, the National Institutes of Health held its consensus development conference in the fall of 1984 . This panel concluded that there was sufficient scientific evidence that high low density lipoprotein (LDL) cholesterol levels cause atherosclerosis. Furthermore, lowering the LDL cholesterol through diet or medications could reduce the incidence of coronary events and mortality.

The National Cholesterol Education Program (NCEP) coordinating committee was formed to direct a nationwide program for the detection, evaluation, and treatment of high blood cholesterol. An adult treatment panel of experts also convened and reported their results and recommendations for detection and treatment of high cholesterol in October 1987 . These guidelines are well covered in the four articles on high blood cholesterol in this issue of JAOA. The cut off points for high blood cholesterol at $240 \mathrm{mg} / \mathrm{dL}$, and an ideal cholesterol level of less than $200 \mathrm{mg} / \mathrm{dL}$ for high risk persons are reasonably attainable goals.

However, individualized clinical judgment is needed when deciding who may need diet therapy or further drug treatment to reach these goals. This is true especially with older patients in whom nutrition becomes more vital and drug therapy may create untoward side effects.

Bile acid sequestrants and nicotinic acid were the drugs of first choice recommended by the adult treatment panel. Clinical trials have demonstrated their effectiveness on lowering LDL cholesterol and coronary heart disease; their long-term safety has been established. The new class of drugs is the HMG-CoA reductase inhibitor (lovastatin), approved by the FDA about the same time the adult treatment panel released its recommendations. They are very effective in lowering LDL cholesterol levels, but insufficient long-term clinical trials are available to show the efficacy of reducing the morbidity, mortality, or incidence of coronary heart disease.

Following the approval of the adult treatment panel's report by the NCEP coordinating committee, the results of the Helsinki Heart Study were reported in The New England Journal. ${ }^{1}$ These showed the clinical efficacy and safety of gemfibrozil in lowering asymptomatic, middle-aged men's elevated blood cholesterol levels. More importantly, this agent not only reduced the LDL cholesterol and triglyceride levels, but HDL cholesterol level rose. The incidence of heart disease was reduced by approximately $34 \%$. This drug now may be more appropriate for patients who require drug treatment to lower their cholesterol, especially when elevated triglycerides or low HDL cholesterol levels are present.

Specifically, elevated triglyceride levels $(>400$ $\mathrm{mg} / \mathrm{dL}$ ) pose a special problem. If diabetes is a factor, weight and blood sugar control are of utmost importance. However, I think nicotinic acid is one of the more effective drugs for lowering triglycerides and LDL cholesterol. However, side effects, such as flushing, make this a frequently overlooked therapy. Nonetheless, if aspirin (5 gr) is administered 30 minutes before nicotinic acid, flushing can be greatly reduced. Initial therapy should include low doses three times a day, given after meals. Nicotinic acid is then titrated up steadily at weekly intervals until the desired level $(1,500$ to $3,000 \mathrm{mg} /$ day) is attained. With lower dosages and subsequently fewer side effects, combination drug therapy may be used in conjunction with nicotinic acid such as cholestyramine or gemfibrizol. In addition, the annual cost to the patient for nicotinic acid averages about $\$ 50$ per year, substantially less than the $\$ 600$ to $\$ 2000$ per year for other drug treatments. 
Of course, the door is not closed on the final recommendations for high blood cholesterol evaluation and treatment. Further recommendations on the clinical importance of HDL cholesterol in the generation of coronary heart disease will be forthcoming by the adult treatment panel. While the NCEP coordinating committee is expected to update its recommendations approximately every 3 years, the current objective is to see that every adult in the United States has a cholesterol determination. To that end, the National Heart, Lung, and Blood Institute has made these standard guidelines available to the clinician so that we can prescribe treatment-diet, weight reduction, and drug therapy when indicated-based on a relatively sound, scientific foundation.

W.H. VOSS, DO, FACOI

AOA Representative to the

NCEP Coordinating Committee

National Heart/Blood/Lung Institute

1. Frick MH, Elo, Hasapa K, et al: Helsinki heart study: Primary prevention trial with gemfibrozil in middle-aged men with dyslipidemia. $N$ Engl J Med 1987;317:1237-1245.

\section{JAOA provides ongoing AIDS education for physicians}

In the JAOA this month, Dr. Leonard Calabrese and Dennis Kelley, BA, RN, discuss how physicians play a critical role in the prevention of the acquired immunodeficiency syndrome (AIDS) by helping patients understand how to reduce the risk of contracting this dreaded disease. Their insights come from first-hand experience in dealing with AIDS patients. The central theme remains the same: Emphasize physician education first, then patient education.

Various strategies for the prevention of sexual transmission of HIV are presented and their practicality and efficiency are discussed. Among them, the intravenous drug abuse population presents a formidable challenge to the successful control of AIDS. The homosexual community has pulled together to fight this disease, but the ability of this group as well as health-care education and other professionals to affect disease transmission by the intravenous drug abusers is of serious concern. Creative programs must be developed to control AIDS among these patients.

Because serological testing plays a substantial screening and diagnostic role in AIDS, all osteopathic physicians must familiarize themselves with this tool. Additionally, developing a pre- and posttest educational and counseling program becomes an essential component of any serological testing program. Dr. Calabrese carefully reviews these issues and offers a discerning approach to accomplish this delicate and at times threatening, emotional process.

Our AIDS educational effort, presented monthly in the JAOA methodically covers, in an up-to-date fashion, the essential information health care providers need to fight this disease. As osteopathic physicians, we must spend time reviewing this information in order to provide the best possible care for our patients.

GILBERT E. D'ALONZO, JR, DO

Contributing Editor, JAOA

AIDS Task force, AOA leading health care company, has excellent private
lospital practice opportunities for qualified physicians in such specialties as:

\begin{tabular}{|c|c|}
\hline $\begin{array}{l}\text { Anesthesiology } \\
\text { Family Practice } \\
\text { Internal Medicine } \\
\text { Oncology } \\
\text { Otolaryngology }\end{array}$ & $\begin{array}{l}\text { Psychiatry } \\
\text { Cardiology } \\
\text { General Surgery } \\
\text { Obstetrics \& Gynecology } \\
\text { Orthopedic Surgery }\end{array}$ \\
\hline
\end{tabular}

For more information about our wide range of physician practice opportunities contact HCA

Physician Recruitment Services, One Park Plaza,

P.O. Box 550, Suite 302, Nashville, TN 37202-0550.

Or call 1-800-251-2561 or 1-800-342-2110 in

Tennesseo. 